\title{
Pure Technical Efficiency and Its Determinants - The Case of Croatian Beverage Industry
}

\author{
Maja Pervan* \\ Faculty of Economics, Business and Tourism, University of Split, Croatia \\ ${ }^{*}$ Corresponding author. Email: mpervan@efst.hr
}

\begin{abstract}
In order to determine pure technical efficiency of firms operating in Croatian beverage industry, a Data Envelopment Analysis is performed on the sample of 57 large, medium-sized and small firms that were active in this industry in 2019. For this purpose, three inputs (material costs, labour costs and fixed assets) and three outputs (profit, operating revenue and value added) were chosen and used in the output-oriented model. The results obtained in the first stage of research (i.e. DEA analysis) were later used in the second stage of analysis, in which a truncated regression is performed in order to identify the determinants of firms (in) efficiency. The results indicated that firm's size, its age and collection period play significant role in firms' efficiency.
\end{abstract}

Keywords: Efficiency, Croatia, Beverage industry.

\section{INTRODUCTION}

Food and beverage industry is the one of the most important sector in Croatia. According to [1], this industry accounted for $20.9 \%$ of all employees in manufacturing sector in January 2020, while contributing with $2.9 \%$ to Croatian GDP in 2017. It also participated with $10 \%$ in total exports of manufacturing sector in 2019.

When focusing solely on beverage industry, it can be perceived that contrary to the positive trends observed in the food production, beverage production decreased by 9\% between 2008 and 2019. At the same time, labour productivity as well as average monthly gross salary paid in the beverage industry in 2019 was higher by $38.7 \%$ and $22.2 \%$ respectively, when compared to 2010 [1].

At the European Union (EU-28) level, an increase of $3.6 \%$ in production of food and beverage industry is recorded in 2019 when compared to 2018. Still, because of the current situation with COVID-19 and its rapidly spreading, a slowdown of the economies, both globally and at the Croatian level is anticipated. Hence, in order to overcome turbulent business surrounding and to enhance their performance, firms have to find a way to increase their efficiency. Still, as much as it is important to detect the actual level of firm's pure technical efficiency, it is equally important to understand its drivers. Therefore, in this research two aims can be identified: first one is to determine pure efficiency of firms operating in Croatian beverage industry; and the second one is to investigate the determinants of their efficiency.

As there is a scarce number of research dealing with the determinants of pure efficiency of firms operating in beverage industry in general; and non-existent research for the Croatian beverage industry in particular; this research directly contributes to the existing body of knowledge by shading new lights on the archived level of efficiency of firms operating in Croatian beverage industry. At the same time, by identifying the factors that to a most extend contribute to this achievement, the research also contributes to the literature of firms' efficiency drivers.

The rest of the paper is organised as follows. Next section brings overview of the existing literature, while the section 3 deals with the analytic framework of the research. Section 4 presents the results of the research. Last section concludes.

\section{LITERATURE REVIEW}

Although research about efficiency is quite popular in healthcare, education, banking and industry [2], [3], and a great number of studies can be found in this area of research (e.g. [4], [5], [6] and [7]), the research dealing with efficiency and its determinants in beverage industry is quite scarce and it is non-existent at the national level. Therefore, literature review provided in this paper will 
encompass a little bit broader dimension of the efficiency and factors that influence it.

The study of [8] explored efficiency of Brazilian food and beverage industry while using DEA and Tobit model. Average value of efficiency is found to be $47 \%$, while a proper financial administration was identified as the main factor responsible for an improvement in efficiency. With the application of DEA methodology, [9] recorded relatively low level of average technical efficiency for the analysed Indonesian micro and small firms. The results of the conducted truncated regression indicated association of technical efficiency with location, firm size, exports, firm age, owner education and level of technology.

Efficiency and its determinants for the Indian food and beverage industry were explored by [10]. The authors applied DEA and OLS regression and discovered that current ratio as well as financial assets to total assets significantly contributed to the observed inefficiency. The study of [11] applied DEA, Tobit and OLS regression while investigating Greek food and beverage industry. The empirical results pointed out that capital productivity, labour productivity, sector size and labour intensity positively affect the level of efficiency. Another research conducted on the sample of food and beverage firms listed in Athens Stock Exchange showed higher level of achieved liquidity efficiency when compared to sales efficiency [12]. Managerial efficiency of Taiwanese food and beverage listed companies was explored by [13] who found an inverse relationship between managerial and scale efficiency.

As regards Croatia, we only found research of [14] who estimated the overall technical, pure technical and scale efficiency of large firms operating in the Croatian food industry and the research of [15] who was dealing with the efficiency of the food industry in Central and Eastern European countries (including Croatia). None of the two Croatian studies investigated beverage industry and factors influencing on efficiency of beverage firms.

\section{METHODOLOGY AND VARIABLES}

\subsection{Sample}

This research encompasses 57 large, medium-sized and small firms that were active in Croatian beverage industry in 2019. All data necessary for the two-stage analysis (i.e. for DEA and truncated regression) were obtained from the database of Croatian Financial Agency [16]. Brief description of both methodologies and variables used in this research is given in the following paragraphs.

\subsection{First Stage of the Analysis - DEA}

After the influential work of [17] and their formulation of CCR model, a more generalized DEA model, known as BCC model, was established by [18]. While the first model is based on the assumption of constant returns to scale (CRS), the second one assumes variable returns to scale (VRS). Aside from the type of returns to scale (CRS and VRS), DEA models may differ according to the model orientation (input and outputoriented model). A more detailed explanation and distinction between the two models is available in [19].

Model selection. As the assumption of BCC model is closer to the real-world situations than that of CCR, a BCC model (which estimates pure technical efficiency PTE and whose efficiency scores show how efficiently inputs are transformed into outputs given the scale size) with output-orientation is applied in this research.

Variables selection. In accordance with microeconomic theory, every production function incorporates inputs such as labour, capital and land/materials in order to produce and sell outputs and consequently to earn profits (as stressed in neo-classical theory of a firm) or to achieve some other goal, such as revenue maximization or firm growth (as indicated in managerial theories of the firm). Hence, three inputs (material costs, labour costs and fixed assets) and three outputs (profit, operating revenue and value added) were used in DEA analysis, which was performed with the Performance Improvement Management Software (PIMDEA).

\subsection{Second Stage of the Analysis - Truncated Regression}

Truncated regression is usually used in models in which the research sample has been truncated above or below certain thresholds of the dependent variable, meaning that the observations (due to the specific value of the dependent variable) are systematically excluded from the sample. Estimation of this model is usually performed via parametric maximum likelihood method.

Model selection. Efficiency scores obtained in the first stage of the research were used as a dependent variable in the second stage of the analysis in which truncated regression was applied. Even though some authors used OLS regression (e.g. [10], [11]) in order to evaluate regression coefficients, this is not recommended as OLS would lead to biased parameter estimates as some firms may have efficiency scores of $100 \%$ while the boundaries of efficiency lie between $0 \%$ and $100 \%$.

Variables selection. Although a significant number of variables may influence firms' efficiency, the selection of variables used in this research (i.e. firm size, age, export and collection period) was guided by theoretical literature and previous empirical research as well as data availability. Each of the variable is measured in the following way: firm size is measured as natural logarithm of firm's total asset; age represent number of years that firm operates in the beverage industry; export is 
calculated as a ratio of firm's export and its revenue; collection period is measured by the number of days within which a firm can collect short-term customers' debt. This part of the research was performed with STATA

Table 1. Results of DEA analysis: distribution of firms according to the Pure tech. efficiency (PTE) values

\begin{tabular}{|l|l|l|}
\hline Values of PTE & No. of firms & $\%$ of firms \\
\hline $90-100$ & 9 & $15.79 \%$ \\
\hline $80-90$ & 4 & $7.02 \%$ \\
\hline $70-80$ & 4 & $7.02 \%$ \\
\hline $60-70$ & 2 & $3.51 \%$ \\
\hline $50-60$ & 10 & $17.54 \%$ \\
\hline $40-50$ & 10 & $17.54 \%$ \\
\hline $30-40$ & 10 & $17.54 \%$ \\
\hline $20-30$ & 6 & $10.53 \%$ \\
\hline $10-20$ & 2 & $3.51 \%$ \\
\hline Total & 57 & $100.00 \%$ \\
\hline $\begin{array}{l}\text { Average value of PTE }=55.96 \% \\
\text { Number of efficient firms }=8\end{array}$ \\
\hline
\end{tabular}

\section{Source: Author's calculation}

\section{RESULTS AND DISCUSSION}

Results of the DEA analysis. After checking and verifying the relationship between selected inputs and outputs by correlation analysis (all coefficients were statistically significant with the range spanning from 0.8 to 0.99 and with the positive sign - thus fulfilling isotonicity condition [20]) a DEA analysis is performed. Due to space saving, the obtained results are presented in Table 1 in a form of classes. Average value of PTE amounted $55.96 \%$ indicating that giving the scale of operation, firm operating in Croatian beverage industry can, on average, augment its outputs by $44.04 \%$ in order to become pure technical efficient. Similar result was recorded by [8] and [9]. Out of 57 firms, eight of them were efficient as their scores were equal to $100 \%$. These firms form benchmarks or reference sets for those inefficient. More than a half of the analysed firms $(52.6 \%)$ were positioned somewhere around middle classes, indicating an existence of the large potential for the further improvement in firms' efficiency.

Results of the truncated regression. Signs of all coefficients are in accordance with our expectation and theoretical literature. Variable Firm size has positive and statistically significant influence on firm efficiency suggesting that larger firms may benefit from economies of scale and scope, and therefore might achieve higher level of efficiency. The coefficient of variable Age is negative and significant, meaning that older firms might become more inert and inflexible by accumulated rules and routines and thus become less efficient than their younger competitors. Variable Collection period has negative and significant impact on firms efficiency indicating that lower the number of days within which a firm can collect short-term customers' debt is, the higher is the firm efficiency. Variable Export didn't prove to be statistically significant. The obtained results are in line with those of [9] and [10].

Table 2. Correlation analysis between inputs used in truncated regression

\begin{tabular}{|l|l|l|l|l|}
\hline & Size & Age & Exp. & Days \\
\hline Size & 1 & & & \\
\hline Age & $0.389 * *$ & 1 & & \\
\hline Exp. & $0.471 * *$ & $0.385^{* *}$ & 1 & \\
\hline Coll.per. & 0.089 & -0.022 & 0.102 & 1 \\
\hline
\end{tabular}

**Correlation is significant at the 0.01 level (2-tailed).

Source: Author's calculation

Table 3. Results of the truncated regression

\begin{tabular}{|l|l|l|}
\hline Variables & Coef. & $\mathrm{P}>|\mathrm{z}|$ \\
\hline Size & 12.0433 & 0.000 \\
\hline Age & -0.6956 & 0.012 \\
\hline Exp. & 0.2073 & 0.363 \\
\hline Coll.per. & -0.0199 & 0.050 \\
\hline cons & -137.04 & 0.000 \\
\hline Sigma & 13.1511 & 0.000 \\
\hline
\end{tabular}

Source: Author's calculation

Note: Robust standard errors were used.

\section{CONCLUSION}

The main aim of this research was to determine pure technical efficiency and its determinants for the firms operating in Croatian beverage industry in 2019. Results obtained with DEA analysis showed that average value of pure technical efficiency (PTE) amounted 55.96\%, suggesting that giving the scale of operation, firm operating in Croatian beverage industry still have quite space for further improvement of their efficiency, as they can, on average, augment their outputs by $44.04 \%$ in order to become pure technical efficient.

Efficiency scores that were obtained in the first stage of the research were later used in the second stage of the analysis in which truncated regression was applied. Regressions results showed that firm size has positive and statistically significant influence on firm efficiency, while variables firm age and collection period have negative and statistically significant impact on firm efficiency. Variable Export was not found to be statistically significant.

In future research, an analysis of overall, pure and scale efficiency of firms operating in manufacturing industry can be performed. In addition, a cross-country analysis with the inclusion of some new variables that may influence firms' efficiency can be conducted.

\section{AUTHORS' CONTRIBUTIONS}

Empirical research investigating pure efficiency and factors that determine efficiency of firms operating in beverage industry is quite rare in general, and nonexistent in Croatia, in particular. Therefore, this study contributes, not only to the literature of efficiency, but it also adds to scientific thought dealing with the 
identification of determinants crucial for achieving higher level of firm efficiency.

\section{REFERENCES}

[1] Sector analysis: Food and Beverage, no.77. The Institute of Economics, Zagreb, Croatia, May 2020, pp. 1-21.

[2] A. Emrouznejad, G.Yang, A survey and analysis of the first 40 years of scholarly literature in DEA: 1978-2016, Socio-Economic Planning Sciences, vol. 61, 2018, pp. 4-8. DOI: https://doi.org/10.1016/j.seps.2017.01.008

[3] J.S. Liu, L.Y.Y. Lu, W.M. Lu, B. J.Y. Lin, A survey of DEA applications, Omega, 41(5), 2013, pp. 893902. DOI: 10.1016/j.omega.2012.11.004

[4] A. Chitnis, D. K. Mishra, Performance Efficiency of Indian Private Hospitals Using Data Envelopment Analysis and Super-efficiency DEA, Journal of Health Management, 21(2), 2019, pp. 279-293. DOI: https://doi.org/10.1177/0972063419835120

[5] F.N. Ho, C. W. Huang, The interdependencies of marketing capabilities and operations efficiency in hospitals, Journal of Business Research, 113, 2020, pp. 337-347, DOI: https://doi.org/10.1016/j.jbusres.2019.09.037

[6] R. Mammadov, A. Aypay, Efficiency analysis of research universities in Turkey, International Journal of Educational Development, 75, 2020, pp. $1-11$.

DOI: https://doi.org/10.1016/j.ijedudev.2020.102176

[7] K. Hafsal, A. Suvvari, S.R.S. Durai, Efficiency of Indian banks with non-performing assets: evidence from two-stage network DEA, Future Business Journal, 6(1), 2020, pp. 1-9. DOI: 10.1186/s43093020-00030-z

[8] D.A. da Cunha, M.B. Salazar, Efficiency of Brazilian food and beverage industry post productive restructuring, Revista de Economia, 39(1), 2013, DOI: 10.5380/re.v39i1.28693

[9] M. Setiawan, N. Effendi, R. Heliati, A. Waskito, Technical Efficiency and Its Determinants in the Indonesian Micro and Small Enterprises, Journal of Economic Studies, 46(6), 2018, pp. 1157-1173. DOI: 10.1108/JES-08-2018-0298

[10] O.N. Arunkumar, T.R. Ramanan, Operational efficiency and its determinants of Indian food and beverages industries: a DEA approach. International Journal of Services and Operations Management, 27(1), 2017, pp.1-18 DOI: 10.1504/ijsom.2017.083332
[11] A. Rezitis, M. Kalantzi, Investigating Technical Efficiency and Its Determinants by Data Envelopment Analysis: An Application in the Greek Food and Beverages Manufacturing Industry, Agribusiness, 32(2), 2016, pp. 254-271. DOI: https://doi.org/10.1002/agr.21432

[12] D. Giokas, N. Eriotis, I. Dokas, Efficiency and productivity of the food and beverage listed firms in the pre-recession and recessionary periods in Greece, Applied Economics, 47(19), 2015, pp. 1927-1941.

DOI: $10.1080 / 00036846.2014 .1002886$

[13] J.L. Hu, C.N. Chiu, H.T. Chu, Managerial Efficiency in the Food and Beverage Industry in Taiwan, Journal of Hospitality Financial Management, 27(1), 2019, pp. 39-48. DOI: https://doi.org/10.7275/dcyb-xp52

[14] M. Pervan, Efficiency of large firms operating in the Croatian food industry: Data envelopment analysis, WSEAS Trans. Bus. Econ, 17, 2020, pp. 487-495. DOI: $10.37394 / 23207.2020 .17 .47$

[15] Z. Lukac, M. Gardijan, Measuring the efficiency of the food industry in Central and East European countries by using the Data Envelopment Analysis approach, Proceedings of the 6th International conference on operations research and enterprise systems, 2017, pp. 385-392.

[16] Croatian Financial Agency (FINA), "info.BIZ" database of Financial Agency. Available at: https://infobiz.fina.hr/Login?ReturnUrl=\%2F accessed 10.03.2021.

[17] A. Charnes, W.W. Cooper, E. Rhodes, Measuring the efficiency of decision making units, European Journal of Operations Research, 2 (6), 1978, pp. 429-441. DOI: https://doi.org/10.1016/03772217(78)90138-8

[18] R.D. Banker, A. Charnes, W.W. Cooper, Some models for the estimation of technical and scale inefficiencies in data envelopment analysis, Management Science, 30(9), 1984, pp. 1078-1092. DOI: https://doi.org/10.1287/mnsc.30.9.1078

[19] J. Zhu, Data envelopment analysis: A handbook of empirical studies and applications. International Series in Operations Research \& Management science, vol. 238, Springer, 2016.

[20] C.N. Wang, N.T. Nguyen, T.T. Tran, Integrated DEA Models and Grey System Theory to Evaluate Past-to-Future Performance: A Case of Indian Electricity Industry, Sci. World J. 2015, pp. 1-17. DOI: https://doi.org/10.1155/2015/638710 